\title{
Methods of diagnosis of hip dysplasia in dogs
}

\author{
Elena Lyubchenko*, Irina Bondarenko, and Tatyana Timofeeva \\ Primorskaya State Agricultural Academy, Blucher str., 44 Primorsky Krai, Ussuriysk, 692510, Russia
}

\begin{abstract}
To diagnose hip dysplasia, you can use a test system, the essence of which is to create a subhabitation in the hip joint of the dog, laid on the side, while there is a click in the joint, which means that the test is positive, while the pressure on the knee joint of the hip joint does not happen. The most common method of diagnosing dysplasia worldwide is X-ray, in which the age of the dogs studied should be more than a year, and large and giant breeds are studied in the range of one to one and a half years, with the animal laid on the back so that the X-ray image shows the pelvis with the wings of the iliac bone and femurs, including the knee joints, therefore, it is also necessary to use sedation, which allows you to comply with all the requirements for styling. The resulting X-rays are assessed according to the main Xray characteristics of the hip joint, taking measurements on six parameters presented in the text of this article, and determining the type of dysplasia. Computed tomography and magnetic resonance imaging can reveal the instability of the pathology in the hip joint and improve understanding of the disease process.
\end{abstract}

\section{Introduction}

Hip dysplasia is a hereditary malformation of the hip joint, which is expressed in an abnormal structure of the femoral head, the acetabular cavity, or both $[16 ; 6]$. The trigger mechanism for the development of dysplasia is the primary instability of the hip joint $[6 ; 8 ; 10]$. The coincidence of the articular surfaces of the hip joint is ensured by the periarticular muscles, the joint capsule, and the round ligament of the femoral head, as well as by the vacuum effect created by the viscoelastic synovial fluid under conditions of congruence of the articular surfaces $[10 ; 16]$. With subluxation of the head, the destruction of the edges of the articular cavity occurs including the lack of pressure of the head on the articular surface, which leads to flattening of the femoral head.

Hip dysplasia in dogs was first detected in the U.S. 60 years ago, although the disease has been known in humans for a long time. It was soon described in Germany, but it was only after the Second World War that the study of hip dysplasia became more widespread, with American, English, and Scandinavian veterinarians making a special contribution to its study. Scientists in Sweden "proved that hip dysplasia is caused by hereditary factors inherent in certain breeds. It is now known that DTS is especially common in those breeds of dogs, which are characterized by a large mass and powerful physique. But the size of the dog itself is not always decisive, because the Irish wolfhounds hip dysplasia is quite rare, and in chow-chow - not often.

Many scientists in different years paid attention to the study of hip dysplasia in dogs, including diagnostic methods. Bardens J. (1972), Koppel E. (1991), Henry G., Han C, Hurd considered the issues of dysplasia by radiography method. (1992), Mitin V.N. et al. (1999, 2000). Henricson V et al. (1966), Bouw J. (1982), Brass
W. (1989), Bloomberg M. (1990), Andersen V. et al (1994), Bondarenko I.V. (2020) were studying the causes and distribution of hip dysplasia in dogs of different breeds and in different regions. We studied methods of treatment of dogs with hip dysplasia Bucci L. (1995), Javnis S.E., etc. (2000), Kurochkin A.K. (2013).

Published a lot of works about hip dysplasia among dogs. Only in the work of Joe P. Morgan and M. Stephens (1988) mentioned 262 publications of 135 authors. Veterinarians, geneticists, and breeders have been involved in the discussion, study, and analysis of the origin of the vice. The FCI- International Cynological Federation has repeatedly held special symposiums and meetings on the spread of the disease among dogs, and the results of analyses and measures taken to eliminate the disease in different countries have been regularly published in the pages of periodicals. Scientists have found and proved that hip dysplasia is a genetic, i.e. polygenic disease, and the number of genes that affect this disease is not defined. The puppy is born with properly set, but weak hip joints. And only under the influence of genetic and exogenous factors, there is hip dysplasia. Hip dysplasia is considered a defect with potential danger to movement. Based on this it should be said that not every animal with dysplasia shows its clinical signs, which means that not every clinically healthy $\operatorname{dog}$ is free of this defect. Among German Shepherds in the United States, according to Sheils research, this defect in 1959 suffered up to $70 \%$ of sheepdogs, and according to Henrikson's work - 7\% in 1969. According to Schuncard's research (1969) from 1962 to 1968 , of the 1,725 German Shepherds of the U.S. Armed Forces, $22.5 \%$ were culled because of this defect. The culling rate close to 50 was obtained in the study of German Shepherds in almost all countries (Wamberg, 1967). In 1971, as Schlaaf points out, the GDR had a dysplasia rate of 35.8. Several breeds have

\footnotetext{
Corresponding author: LyubchenkoL@mail.ru
} 
achieved significant distribution. German Shepherds, St. Bernards, Newfoundlands are especially often affected. This anomaly is also observed in Rottweilers, boxers, dogs, bulldogs, but greyhounds are free from this defect. Dysplasia in $89 \%$ of cases affects both hip joints; in $3.3 \%$ of cases - only the left joint of the hip; $7.7 \%$ of cases - only the right joint of the hip.

Hip dysplasia occurs in all countries, mainly in dogs of large breeds. There are cases when the dog may not show any symptoms of lameness, but due to the condition of the joints, it may be excluded from breeding. Breeders should be interested not only in the health of their pets but also in the health of their offspring. Therefore, the earliest detection of joint dysplasia is of great importance for the reproduction of healthy animals in dog breeding. The diagnosis of this disease in dogs consists of different research methods since it is very important to determine the type of dysplasia and make the right decision about the treatment of the animal.

The trigger for the development of dysplasia is the primary instability of the hip joint. The coincidence of the articular surfaces of the hip joints is ensured by the periarticular muscles, the joint capsule, and the round ligament of the femoral head, as well as by the vacuum effect created by the viscoelastic synovial fluid under conditions of congruence of the articular surfaces [9, 15]. When the head is dislocated, the edges of the articular cavity (dorsal and craniolateral) are destroyed, and the femoral head does not exert pressure on the articular surface, which leads to flattening of the femoral head.

Statistics of the data of studies of all authors show that from parents with a severe degree of disease is born a higher percentage of puppies with severe lesions. Scientists disagree on the dependence of the animal's sexual predisposition to the disease. Thus, according to Vanderlip males (of all breeds) get sick 1.2 times more often. Turkevich points to an equal percentage of sick animals of both sexes of all breeds. According to Mitin's research (1982), a higher incidence rate among females (all breeds). The author refers not to the connection of the trait with the sex, but the hormonal influence. According to the DRO (1991-1993), German Shepherds have a $25.4 \%$ incidence among males and $28.5 \%$ among females. Thus, the figures are quite close, with only some excess of the percentage of patients among. If there were no symptoms of hip dysplasia (selection for two generations), the percentage of healthy puppies born reached 76. If one of the partners was free from dysplasia, the percentage of healthy puppies ranged from 47 to 50. Bjernfors considers the type of inheritance of dysplasia as autosomal-dominant with a full probability of phenotypic gene manifestation in the population $60 \%$. In the appearance of hip dysplasia, the main role is played by hereditary predisposition. However, this ailment can be observed in dogs, received from quite healthy parents. The degree of inheritance of hip dysplasia, according to the Swedish authors, is $55-60 \%$. Statistical assessment of the origin of the disease within the entire population of dogs is fickle and depends on many factors.
The purpose of this article is to monitor existing methods of testing dogs for the presence of hip dysplasia (HP).

\section{Materials and methods}

The materials and methods of our research were the literary sources, both domestic and foreign. This research was carried out as part of a diploma project.

Diagnosis of hip dysplasia in dogs should be followed with a thorough history and clinical manifestations.

According to research by many scientists, only $20 \%$ of dogs with diseased joints. The lightest deviations do not lead to tangible clinical manifestations in the dog, and for the owner, as a rule, remain invisible. A detailed picture of the disease is usually observed in dogs 4-6 months. The timing of distinct clinical traits depends on the individual characteristics of the animal. However, this usually happens no later than the first year of life, which is probably due to an increase in physical activity, training, and training. In other cases, the symptoms are absent or so mild that do not affect the well-being and working use of the dog. In mild cases, a puppy or a young dog has a slight weakness of the hind limbs, sometimes a slight limp on one or both limbs with prolonged movement or increased load. Movements can remain free, but the dog becomes less hardy and with reluctance performs support jumps over the barrier, the gait becomes shaken. Starting from the second stage, there may be sub-revisiting or dislocation, reaching even to a complete lateral displacement of the head of the femur due to its extremely crushed heel cavity. In severe cases, there is pain and rapid fatigue after movement or prolonged standing. The dog hardly gets up) when moving limps. There is a weakness of the limbs and their instability on the smooth floor. Movements are difficult, the gait is usually constrained, tense. When landing, the hip is turned inside (rotation), and the dog takes an unnatural posture. In the future develops atrophy of gluteal muscles, can be observed in an asymmetry of the pelvis, well-delineated large skewer of the hip; When the dog moves, the joint is visible, which is unnatural; compensatory hypertrophy of the front limb belt muscles is possible. If you get used to it or dislocate, the paw turns outwards. Gently the limb, the dog can completely stop relying on it. Passive hip removal to the side is usually limited, may be observed shortening of the sore limb. In severe forms of the disease, passive rotation of the hip may be a symptom of a click. When the hip is removed to the side, it is possible to probe the displacement of the head of the thigh on the swivel trough. Bilateral dysplasia is especially noticeable, in which dogs hardly rise. When diagnosing, both joints should be examined at the same time.

When working with literature sources, we found that diagnostic imaging is the main method used to diagnose hip dysplasia in dogs [17]. Today, there are the main methods of complex joint research: traditional (OFA test-Orthopedic Foundation for Animals) and Penn HIP method. 
The PennHIP method, proposed by the University of Pennsylvania as part of the Program for the Development of the Diagnosis of HP, including special radiographic studies in combination with the study of joint movement, became the current assessment system in 1993. For X-ray examination with the PennHIP method, immobilization (sedation) of the animal is necessary. This technique can detect the problem as early as 16 weeks of age. Two images of the hind limbs are taken in a neutral position to visualize the structure of the joint as close to reality as possible. These images are performed with the creation of compression (pressure) and distraction (traction) in order to immerse the head of the femur in the acetabular cavity or, on the contrary, to push it out as much as possible, special devices are used. The distraction index (CI) is used to assess joint subluxation. Next, a standard OFA scan is performed to assess secondary changes in the joint [8]. From the point of view of predicting the development of hip dysplasia and osteoarthritis, the method was quite accurate.

A test system can be used to diagnose hip dysplasia. There are two common tests for hip dysplasia:

The Ortolani test, the essence of which is to create a subluxation in the hip joint of a dog lying on its side. The veterinarian creates pressure on the knee joint with his hands, which leads to its subluxation. Without reducing the pressure, the veterinarian removes the dog's limb in the lateral direction, and the hip joint falls into place. There is a click in the joint, which means that the test is positive. Normally, pressure on the knee joint does not cause subluxation of the hip joint [16].

The Bardens test provides for the detection of subluxation of the hip joint. This test is performed in the lateral position. The veterinarian holds his fingers simultaneously on the sciatic tubercle and the large trochanter of the thigh, while with the other hand he moves the thigh to the medial-lateral side as if shifting the head of the thigh from the acetabulum down. With subluxation of the hip joint, a shift of the large trochanter to the lateral side is felt. This symptom is positive [16].

\section{Results and discussion}

For a complete diagnosis of hip dysplasia, an X-ray examination is performed, it must meet a number of mandatory requirements. The age of the studied dogs should be more than a year, while large and giant breeds are studied in the range from one to one and a half years $[9 ; 10]$. A prerequisite for this procedure is the use of sedation, which allows you to meet all the requirements for laying [11], in which the animal is placed on the Xray table on its back so that the pelvis with the wings of the ilium and the femurs, including the knee joints, are visible on the X-ray image. Radiography is the most common method for diagnosing dysplasia worldwide [1; 15].

Stress radiographs are used to determine instability in the hip joint. To do this, the animal in the position on the back between the extended and rotated pelvic limbs is placed in a wedge (usually log-shaped), and then the distal parts of the limbs are brought as close as possible. This leads to a forced subluxation of the femoral heads [4]. Stress radiographs are used to determine dysplasia in young dogs and with a significant discrepancy between clinical symptoms and the radiologically determined degree of the disease $[9,16]$.

Computer (CT) and magnetic resonance imaging (MRI) of the hip joints can be used in the same sense as $\mathrm{X}$-ray diagnostics, for example, to measure angles and detect the instability of the pathological process [2].

Table 1. -Parametric score of TBS dysplasia in dogs

\begin{tabular}{|c|c|c|}
\hline Parameter 1 & Parameter 2 & Parameter 3 \\
\hline Norberg angle & $\begin{array}{l}\text { Index of } \\
\text { insertion (I.I) of } \\
\text { the femoral head } \\
\text { into the cavity }\end{array}$ & $\begin{array}{l}\text { Tangential } \\
\text { angle, antero- } \\
\text { outer edge of the } \\
\text { cavity }\end{array}$ \\
\hline$\geq 105^{\circ}$ & I.I & $\begin{array}{l}\text { The angle is } \\
\text { negative, the } \\
\text { edge is sharp, } \\
\text { covers the head }\end{array}$ \\
\hline $\begin{array}{l}\geq 105^{\circ}, \text { joint gap } \\
\text { uneven }\end{array}$ & $\mathrm{I} . \mathrm{I} \geq 1.0$ & Angle horizontal \\
\hline$\geq 100^{\circ}$ & $\mathrm{I} . \mathrm{I}=1.0$ & $\begin{array}{l}\text { Angle } \\
\text { horizontal, } \\
\text { margin slightly } \\
\text { rounded } \\
\text { modified }\end{array}$ \\
\hline$\geq 90^{\circ}$ & I.I $\geq 0.7$ & $\begin{array}{l}\text { Angle positive, } \\
\text { margin slightly } \\
\text { changed and } \\
\text { rounded, } \\
\text { contours } \\
\text { bifurcated }\end{array}$ \\
\hline$\geq 80^{\circ}$ & I.I $\geq 0.5$ & $\begin{array}{l}\text { The angle is } \\
\text { positive, the } \\
\text { edge is strongly } \\
\text { rounded, the } \\
\text { contours are } \\
\text { clearly } \\
\text { bifurcated }\end{array}$ \\
\hline$<80^{\circ}$ & I.I $<0.5$ & $\begin{array}{l}\text { The angle is not } \\
\text { defined, the edge } \\
\text { is missing, all } \\
\text { the contours are } \\
\text { bifurcated }\end{array}$ \\
\hline
\end{tabular}

As is customary in the practice of veterinarians, the obtained radiographs are evaluated according to the main radiological characteristics of the hip joint. To do this, the images are printed on a laser printer, and measurements are carried out with the help of special tools:

Parameter 1. The Norberg angle (cranio-acetabular) between the straight line connecting the geometric centers of the femoral heads and the tangent drawn from the center of the head along the anterior edge of the articular cavity.

Parameter 2. Index of insertion of the femoral head into the articular cavity is the ratio of the femoral head covered by the upper edge of the articular cavity to the radius of the head. 
Parameter 3. The tangential angle was measured by a horizontal line drawn anteriorly to the outer edge of the articular cavity, and a tangent that is the cranial contour of the articular fissure.

Parameter 4. The cervical-diaphyseal angle, which is formed by the intersection of the axes of the neck and the femoral shaft.

Parameter 5. The shape of the head and the architectonics of the hip.

Parameter 6. Exostoses on the femoral neck [7].

After the measurements, the results are evaluated according to the modified Flukiger (1996) method. To do this, we evaluate the radiographs and, checking the table 1, calculate the sum of points.

After an instrumental and test study, the type of hip dysplasia is determined. Acetabular (Dysplasia Acetabula) is due to the normal cervical-diaphyseal angle (135 degrees) and the weakness of the ligamentous apparatus, as well as cervical-diaphyseal (Coxavalgaantetorta). This is characterized by a change in the cervical-diaphyseal angle and the presence of a normal acetabulum, with an angle of more than 150 degrees [11].

Animal styling. X-ray examination of dogs with hip dysplasia is performed in two standard projections. Be sure to take into account the age of the studied animals. In the first clutch, dogs under deep sedation are laid on their backs with the ventrodorsal course of the rays so that the pelvis with the wings of the ilium, femurs, and knee joints are clearly visualized on the X-ray image. The dog should be laid perfectly symmetrical. This is checked by the same shape of the locked holes (they achieve the same shape, width, area) [8]. This fact is given increased attention since the asymmetric laying leads to falsification of the results of X-ray examination.

In the position on the back, the pelvic limbs are parallel to each other, maximally extended caudally, and are in the same plane as the plane of the table. The pelvic limbs are rotated medially so that the radiological projections of the kneecaps fall on the intercondylar groove of the femurs, and the sciatic tubercles are projected on the medial surfaces of both femurs. Achieve such an extension of the pelvic limbs that the distal edge of the patella is on a perpendicular line drawn along the distal edge of the sesamoid bones. The projection of the kneecaps in the center of the intercondylar groove of the femur is a sign of optimal rotation of the limbs medially, which results in optimal visualization of the femoral neck [3, 4].

In the second position, known as the "frog position", or the "frog legs" position, the pelvic limbs should be bent at the knee and hip joint so that the angle between the pelvis and the femur is $45^{\circ}$ [4]. This position allows you to identify exostoses of the acetabular fossa.

The dorsal edge of the articular cavity is evaluated by placing the dog in a chest position and pulling the limbs cranially along the body. This technique is called DAR (Dorsal Acetabular Rim) [8]. The pelvis in this position rests on the sciatic tubercles, is positioned vertically to the table, and allows you to best visualize the changes in the dorsal edge of the acetabulum. Sclerotic changes, exostoses in the neck and joint cavity are determined better than that on the X-ray in the first position.

Table 2. Parametric score of TBS dysplasia in dogs

\begin{tabular}{|c|c|c|c|}
\hline $\begin{array}{l}\text { Parameter } \\
4\end{array}$ & Parameter 5 & Parameter 6 & Points \\
\hline $\begin{array}{l}\text { The state } \\
\text { of the } \\
\text { closing } \\
\text { plate of the } \\
\text { arch of the } \\
\text { cavity }\end{array}$ & $\begin{array}{l}\text { The shape of } \\
\text { the head and } \\
\text { the } \\
\text { architectonics } \\
\text { of the femur }\end{array}$ & $\begin{array}{l}\text { Exostoses on the } \\
\text { femoral neck }\end{array}$ & \\
\hline $\begin{array}{l}\text { Normal, } \\
\text { evenly } \\
\text { thickened }\end{array}$ & $\begin{array}{l}\text { The head is } \\
\text { round, the } \\
\text { trabecular } \\
\text { systems are } \\
\text { represented } \\
\text { by three } \\
\text { systems }\end{array}$ & $\begin{array}{l}\text { Indistinguishable, } \\
\text { the transition of } \\
\text { the head to the } \\
\text { neck is clearly } \\
\text { expressed }\end{array}$ & 0 \\
\hline $\begin{array}{l}\text { Evenly } \\
\text { thickened }\end{array}$ & $\begin{array}{l}\text { Head round, } \\
\text { angular, } \\
\text { outline } \\
\text { indistinct, } \\
\text { architectonics } \\
\text { not perfect } \\
\end{array}$ & $\begin{array}{l}\text { Indistinguishable, } \\
\text { the neck is } \\
\text { cylindrical, the } \\
\text { transition } \\
\text { unchanged }\end{array}$ & 1 \\
\hline $\begin{array}{l}\text { Laterally- } \\
\text { slightly } \\
\text { thickened, } \\
\text { medially- } \\
\text { slightly } \\
\text { reduced }\end{array}$ & $\begin{array}{l}\text { Femoral head } \\
\text { slightly } \\
\text { flattened, } \\
\text { architectonics } \\
\text { enhanced by } \\
1 \text { and } 2 \\
\text { systems of } \\
\text { trabeculae }\end{array}$ & $\begin{array}{l}\text { Thin pointed } \\
\text { border up to } 1 \\
\text { mm, the } \\
\text { transition is } \\
\text { slightly changed }\end{array}$ & 2 \\
\hline $\begin{array}{l}\text { Laterally- } \\
\text { medium } \\
\text { thickened, } \\
\text { medially- } \\
\text { medium } \\
\text { reduced }\end{array}$ & $\begin{array}{l}\text { Head } \\
\text { medium } \\
\text { flattened, } \\
\text { architectonics } \\
\text { represented } \\
\text { in the lower } \\
1 / 3 \text { of the } \\
\text { head }\end{array}$ & $\begin{array}{l}\text { The border is up } \\
\text { to } 3 \mathrm{~mm} \text { wide, } \\
\text { the transition is } \\
\text { slightly changed }\end{array}$ & 3 \\
\hline $\begin{array}{l}\text { Laterally- } \\
\text { strongly } \\
\text { thickened, } \\
\text { medially- } \\
\text { complete } \\
\text { reduction }\end{array}$ & $\begin{array}{l}\text { The head is } \\
\text { flattened, the } \\
\text { architectonics } \\
\text { are } \\
\text { represented } \\
\text { only along } \\
\text { the edge of } \\
\text { the head }\end{array}$ & $\begin{array}{l}\text { The border is } \\
\text { more than } 3 \mathrm{~mm} \\
\text { wide, the } \\
\text { transition is } \\
\text { moderately } \\
\text { changed }\end{array}$ & 4 \\
\hline $\begin{array}{l}\text { Fused with } \\
\text { the lateral } \\
\text { surface of } \\
\text { the pelvis, } \\
\text { sometimes } \\
\text { absent }\end{array}$ & $\begin{array}{l}\text { The head is } \\
\text { strongly } \\
\text { flattened, the } \\
\text { architectonic } \\
\text { is not defined }\end{array}$ & $\begin{array}{l}\text { The border is } \\
\text { layered on the } \\
\text { edge of the neck } \\
\text { due to large } \\
\text { exostoses }\end{array}$ & 5 \\
\hline
\end{tabular}

When studying with the help of the DAR technique, the determination of the DAR angle is of great diagnostic importance. The angle is formed by two tangents drawn along the lower border of the dorsal joint edge. In a normal hip joint, it is $165180^{\circ}$, and in 
dysplasia less than $165^{\circ}$. In addition to changes in the dorsal edge of the articular cavity, the DAR technique can detect dysplasia in dogs at a very early age (4-6 months) $[2,8]$. Stress radiographs are used to determine instability in the hip joint. To do this, the animal in the position on the back between the extended and rotated pelvic limbs is placed in a wedge (usually log-shaped), and then the distal parts of the limbs are brought as close as possible. This leads to a forced subluxation of the femoral heads [4]. Stress radiographs are used to determine dysplasia in young dogs and with a significant discrepancy in clinical symptoms with the radiologically determined degree of the disease in the first position $[8,15]$.

To determine the degree of dysplasia, there is a special classification. The International Canine Federation (FCI), which includes Russia, uses the classification from A to E: A - normal joint; B - joint within acceptable limits; C - mild dysplasia; D moderate dysplasia; E - severe dysplasia [4].

Table 3. Final assessment of hip dysplasia in dogs aged more than 12 months.

\begin{tabular}{|c|c|l|}
\hline $\begin{array}{l}\text { Sum of } \\
\text { points }\end{array}$ & $\begin{array}{l}\text { Degree of } \\
\text { dysplasia }\end{array}$ & Interpretation \\
\hline $0-2$ & A & $\begin{array}{l}\text { No dysplasia } \\
\text { Borderline case, suspicion } \\
\text { Mild degree of hip } \\
\text { dysplasia } \\
7-6\end{array}$ \\
$10-12$ & C1 & $\begin{array}{l}\text { Mild degree of hip } \\
\text { dysplasia (culling) } \\
\text { Moderate degree, culling } \\
\text { Severe degree, culling }\end{array}$ \\
$13-18$ & D & \\
\hline
\end{tabular}

The final diagnosis of hip dysplasia is made after an $\mathrm{X}$-ray examination. Radiography is the most common method for diagnosing dysplasia worldwide [1, 14]. Other diagnostic methods (CT, MRI) are more informative, but due to their high cost and low availability of equipment, they are less common. X-ray examination of dysplasia should meet several mandatory requirements. The age of the studied dogs (meaning the official study) should be more than a year, while large and giant breeds are studied in the range from one to one and a half years [8, 9]. One of the most important requirements for conducting an X-ray examination is deep sedation of the animal. This is due to the inability to meet all the requirements for laying on an unseeded animal [10].

In cases where coxarthrosis is developed strongly enough and the withdrawal and extension of the limbs, even under sedation, leads to anxiety and tension in animals, deep anesthesia with strong analgesia is used. It should not be forgotten that the tense periarticular musculature contributes to the attraction of the femoral head to the articular cavity, which can distort the results of the study [8]. With relaxed muscles, it is much easier to detect instability in the hip joints $[5,13]$.

\section{Conclusion}

Traditional hip radiographs remain the most commonly used assessment method and are useful as a screening tool and for detecting radiographic signs of dysplasia. Additional diagnostic methods, such as Penhip distraction radiography, increase the sensitivity of weakness detection, provide more informative results, and help predict the development of dysplasia in younger animals. Computed tomography and magnetic resonance imaging, although not readily available due to the high cost of equipment, improve the understanding of the disease process, which potentially helps with the appointment of therapy.

\section{References}

1. S. E. Zhavnis, D. A. Belyaeva Proceedings of the VIII International Congress on Problems of Veterinary Medicine of small domestic animals. Pp. 52-54. (Moscow, 2000)

2. A. K. Kurochkin Retrieved from: http://infovet.ru/blog/vyiibor-metoda-lecheniyapri-displaz-287.html

3. V. N. Mitin, S. A. Yagnikov, V. A. Lyubimov Vet, 7-9, 25-33, (1999)

4. V. N. Mitin, Yu. I. Filippov, V. A. Lukyanovsky, S. A. Yagnikov Radiological diagnosis of hip dysplasia in dogs. Methodological recommendations (Moscow, "Aquarium" 2000).

5. W. Andersen, B. Anderson Atlas of Canine Anatomy. (Lea \& Fe-biger 1994).

6. J. J. Bardens Amer. Anim. Hosp Assoc., 3, 468471. (1972)

7. I. V. Bondarenko, E. N. Lyubchenko The role of agrarian science in the development of the forest and rural East. Materials of the (All-Russian) conference. In 4 parts. pp. 276-279, (2020)

8. M. Bloomberg Vet. Techn. 11, 303-309 (1990)

9. J. Bouw Vet. Quart. 4, 173-181, (1982),

10. W. J. Brass Small Anim, Pract., 30, 166-170. (1989)

11. L. Bucci Nutrition Applied to Injury Rehabilitation and Sports Medicine., 53-58, (1995)

12. M. Fliickiger, J. Lang, H. Binder, A. J. Busato Schweiz. Arch. Tierheilk. 137, 243-250, (1995)

13. U. Freudiger, V. Scharer, J. Buser, R. J. Muhlebach Schweiz. Arch. Tierhk. 115, 69-73, 1973.

14. C. Han, Hurd. Practical guide to diagnostic imaging: radiography and ultrasonography. (American Veterinary publications)

15. B. Henricson, I. Norberg, S. J. Olsson Small Anim. Pract. 7, 673-688, (1966)

16. G. Henry Vet. Clin. Nort Am. Small Anim. Prac. 22, 559-578, 1992.

17. E. Koppel ZurEntwicklung der Articulatiocoxae und radiologi-schenFriihdiagnostik der Huftgelenkdysplasie des Hundes. (EnkeVerlag, Stuttgart. 1991). 